\title{
WAYS OF USING THE ARDUINO PLATFORM FOR EDUCATION OF FIRST-YEAR STUDENTS OF THE RIGA TECHNICAL UNIVERSITY
}

\author{
Oksana Zavjalova \\ Riga Technical University, Latvia \\ Viktorija Ziborova \\ Riga Technical University, Latvia \\ Sabina Katalı̣ikova \\ Riga Technical University, Latvia \\ Natalya Prokofjeva \\ Riga Technical University, Latvia
}

\begin{abstract}
This paper describes the actual problem of organizing the process of professional education of students in applied problems in their specialty. The problem is considered from two aspects: pedagogical (substantive) and technical, while the solution of learning problems is planned to be realized with the help of new information technologies. The article describes two study schemes based on two programming technologies: VBA and the Arduino platform, explores the advantages and disadvantages of each scheme, and provides examples of specific tasks and the results of a survey of first-year students, which study scheme is most suitable for professional education. The study involved first-year students of RTU Faculty of Electrical and Environmental Engineering, studying the educational course "Computer science".
\end{abstract}

Keywords: Arduino platform, student survey, study scheme, VBA language.

\section{Introduction}

At present, the system of higher professional education is focused on improving the quality of training and the level of competitiveness of a specialist in the labor market. The necessary professional qualities and competence of university graduates are formed by using an integrated approach to the process of organizing educational activities, including the implementation of methodological and pedagogical learning tasks using effective educational and information technologies. In this regard, it is necessary and urgent to consider issues related to identifying optimal ways to improve the educational process, the choice of training models for students.

The learning process at any stage involves direct interaction between the teacher and students. The feedback received as a result of student surveys allows 
Zavjalova et al., 2021. Ways of Using the Arduino Platform for Education of First-Year Students of the Riga Technical University

the teacher to choose various teaching methods that are optimal at the moment, as well as to develop a strategy for conducting academic subjects, which allows using new forms of work with students (Prokofjeva, Uhanova, Zavjalova, \& Boltunova, 2019; Prokofjeva, Uhanova, Zavjalova, \& Katalnikova, 2015).

This article analyzes the possibility of using the Arduino platform (https://www.Arduino.cc/) when teaching first-year students of RTU Faculty of Electrical and Environmental Engineering. The authors of the article claim that the addition of the "Computer science" course with new content elements, in particular the use in practice of various capabilities of the Arduino platform, can significantly increase the motivation of students and their interest in raising their own professional competence.

\section{Learning Course “Computer Science” and Two Study Schemes}

Currently, due to the increasing rates of scientific and technological progress, there is a continuous increase in the volume and change in the content of knowledge and skills that modern specialists should master. The issues of computer learning are of interest to many scientists, both pedagogues and specialists in the field of information technology (Byungura, Hansson, Muparasi, \& Ruhinda, 2018; Hammad, \& Munir, 2018; Shadiev, Zhang, Wu, \& Huang, 2020).

The solution of professional tasks that require performing, for example, a large amount of calculations, visualization of electrical, physical processes, accuracy of results, etc., is assigned to computers. There are many technologies for solving such problems. Therefore, the need to teach future engineers the basics of programming and computer technology is undeniable.

The Department of Software Engineering has been teaching the study course "Computer Science" for several years for some study programs of the Faculty of Electrical and Environmental Engineering (Fig. 1).

The main learning goal of the study course "Computer Science" is the ability to compose and solve the simplest algorithms (i.e., making a logical chain to achieve a result), as well as apply the developed algorithm to solve applied problems.

This course is the starting point for further mastering the educational material on the "Adaptorics" and "Energy and Electrical Engineering” study programs. 
Proceedings of the International Scientific Conference. Volume V, May $28^{\text {th }}-29^{\text {th }}$, 2021. 511-521

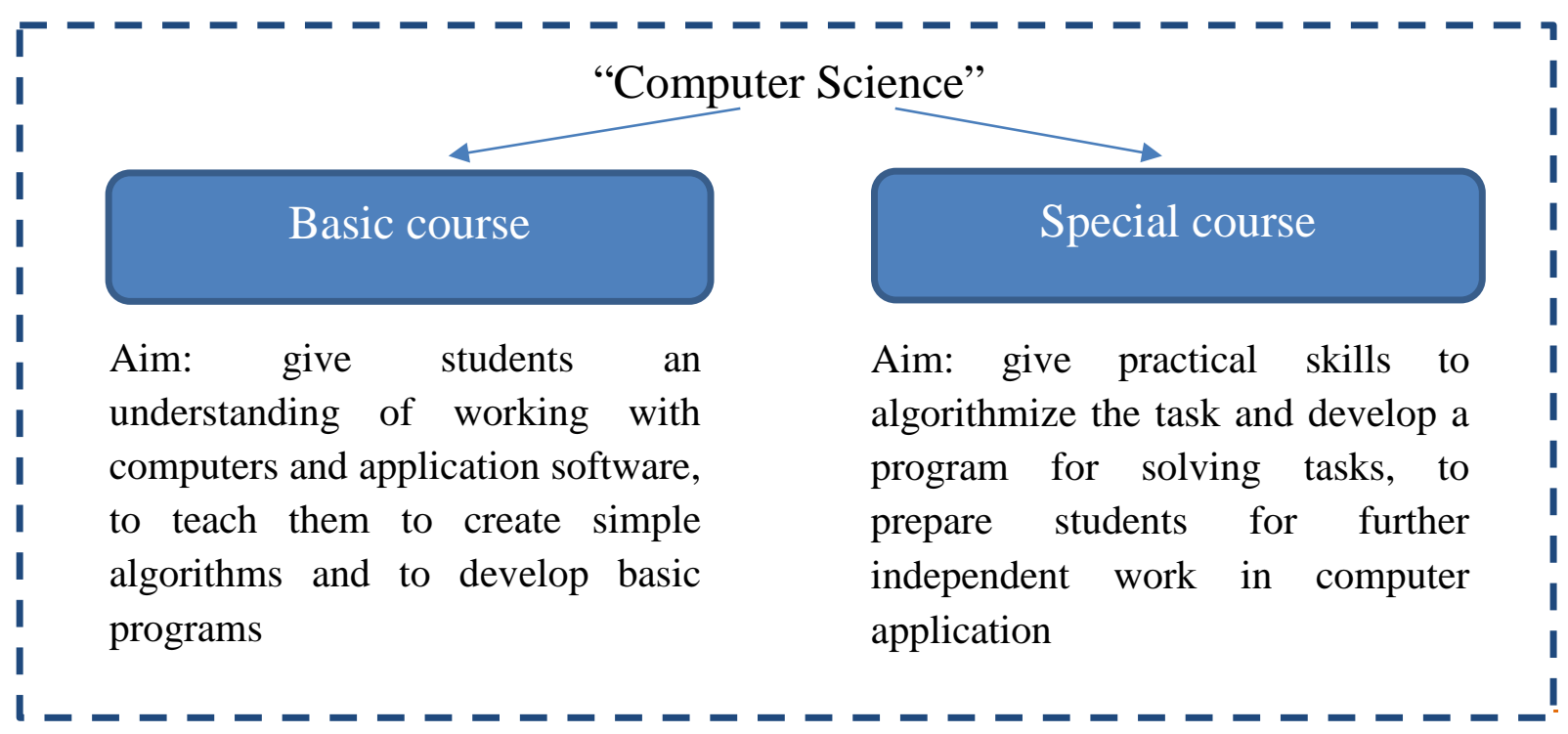

Figure 1 Structure of the Learning Course "Computer Science"

The "Adaptronics" study program, in addition to basic knowledge of the theoretical and practical issues of the implementation of electrical technologies in various sectors of the national economy, provides students with knowledge about the principles and automation of electrical technologies.The study program "Energy and Electrical Engineering" offers such learning areas as: power supply and electrical equipment; automation of electric power systems; electrical machines and apparatus.

For teaching the first-year students, two study schemes were used, based on two programming technologies:

- $\quad$ VBA (Visual Basic for Application);

- Arduino platform.

In the first scheme, the VBA (Visual Basic for Application) programming language in MS Excel (Microsoft Ignito, 2020) was used to accomplish the task. The choice was justified by the availability of MS Excel for a wide range of users, which makes it possible not to use additional and expensive software packages. In addition, the VBA programming language makes it possible to develop simple algorithms and is easy to understand. It is also convenient to use it as the first steps of programming for "non-programmers", on the other hand, VBA is an object-oriented language, i.e. provides an opportunity to acquaint students with a new level of programming language.

From 2019/2020 academic year, it was decided to use the second study scheme based on the Arduino hardware platform (Arduino, 2020). It is a modern, developing and accessible platform for both beginners and those taking their first steps in programming, and for professionals. The Arduino platform is a combination of the of rapid development environment Arduino IDE and 
Zavjalova et al., 2021. Ways of Using the Arduino Platform for Education of First-Year Students of the Riga Technical University

prototyping modules based on microcontrollers (Engineering Experiences, 2020; Hurtuk, Chovanec, \& Adam, 2017). A huge arsenal of various sensors, detectors, displays, drivers and actuators is available for prototyping and learning. In fact, Arduino is the simplest and most inexpensive electronic constructor for creating ready-made devices from individual modules. The technical kits of the Arduino electronic designer give an initial idea of the principles of operation and control, feedback and signal processing from sensors - this is an ideal option for the first steps in robotics, electrical engineering and learning to program the simplest algorithms.

Further, the authors of the article give an assessment of each study scheme depending on the pedagogical and technical content, and also based on the results of a survey of the first-year students Faculty of Electrical and Environmental Engineering conclusions are drawn, which study scheme is most suitable for professional education.

\section{Advantages and Disadvantages of Study Schemes}

As already noted, until 2019, the first scheme was used to conduct the "Computer science" course, that is, the VBA language was used to learn the basics of programming. The substantive (methodical) part of the course includes topics such as branched and cyclic algorithms, processing information in arrays, as well as the user's work with a range of MS Excel cells, creating a dialog box (UserForm) and using Workbook and Worksheet objects to process related information in multiple files.

From a technical point of view, the first study scheme is very simple to implement. Classes were held in a computer class, students worked in MS Excel, solving the proposed problems.

Further examples of tasks for solving in MS Excel are given.

Task 1. Create a table that stores student grades. Suppose students take 5 exams in a session. Highlight in red the names of students with no marks less than 5. Display this number of students on the screen using the MsgBox function. The solution is shown in Fig. 2 and 3. 
Proceedings of the International Scientific Conference. Volume V, May $28^{\text {th }}-29^{\text {th }}$, 2021. 511-521

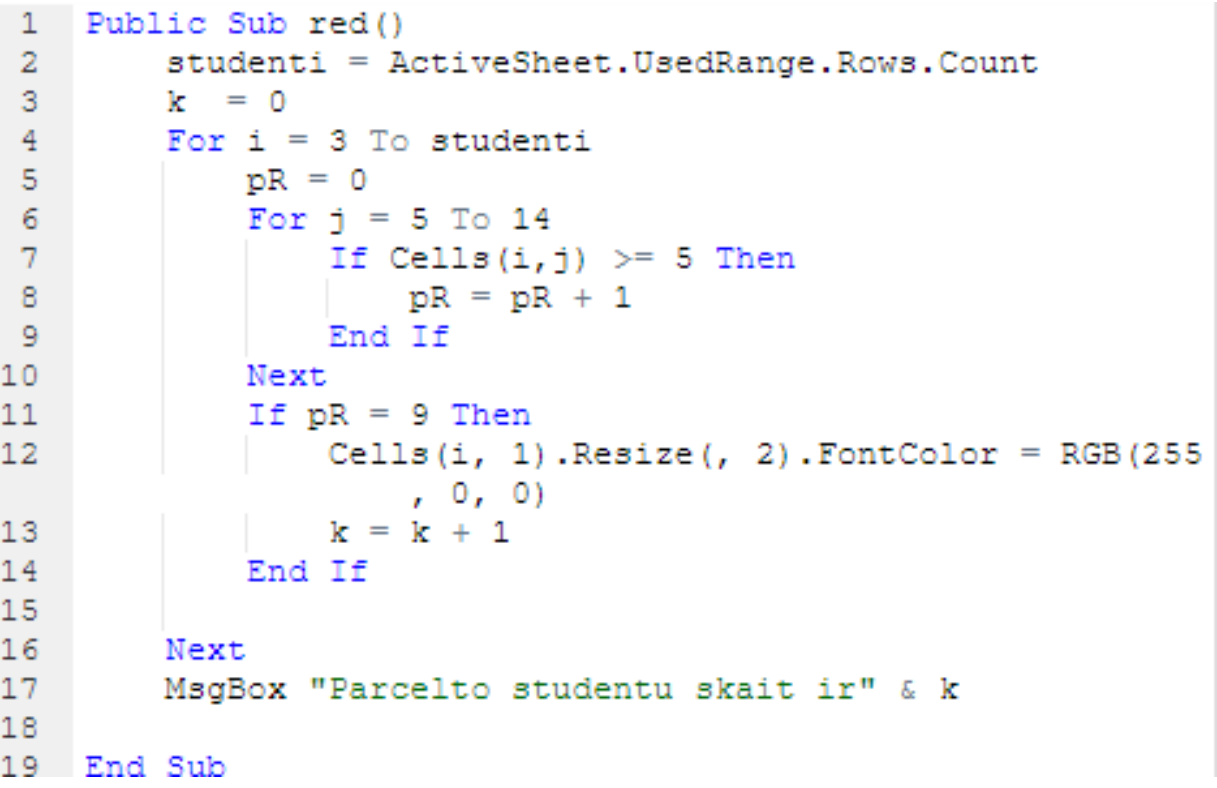

Figure 2 Solution Source Code

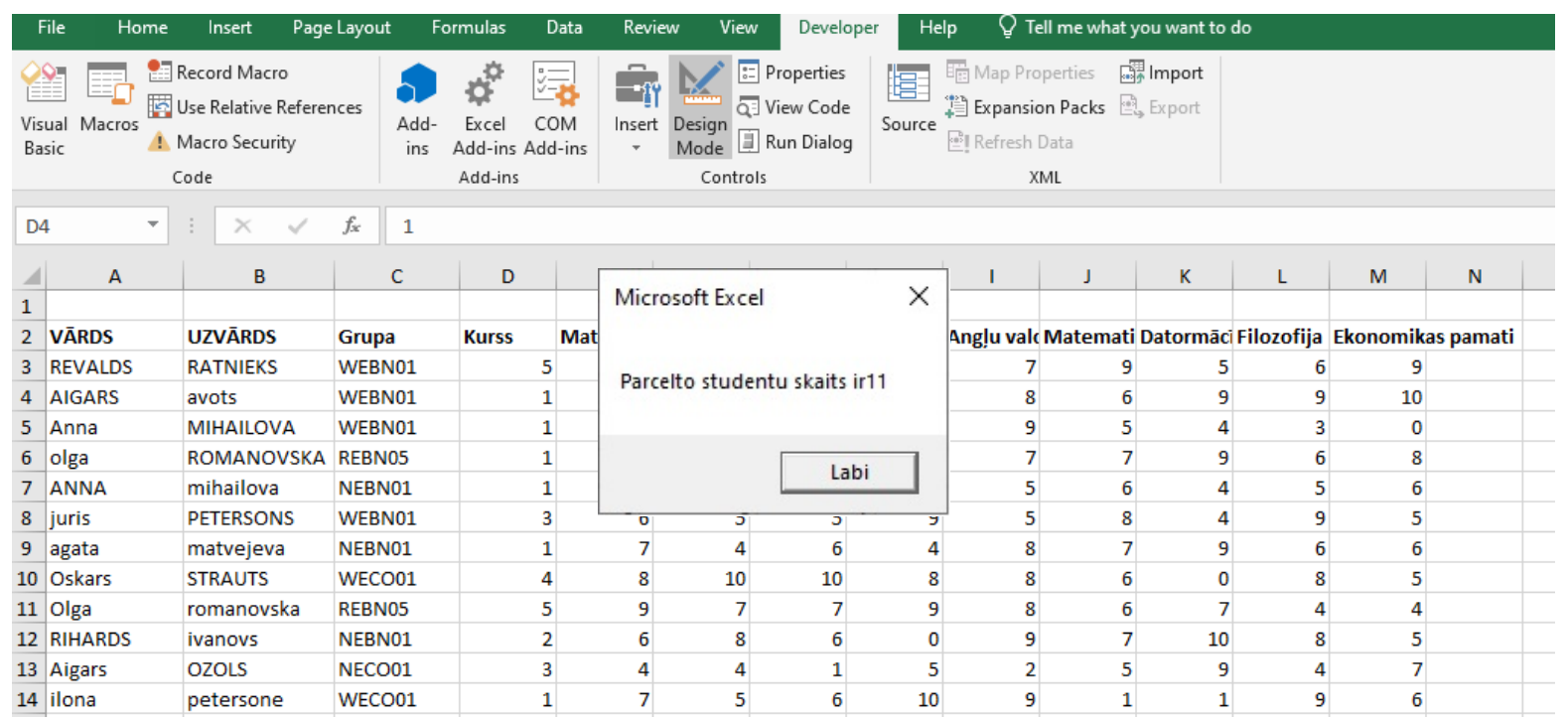

Figure 3 Created Table

Task 2. Using the loop operator DO or FOR, develop a macro function with one parameter $n$ that computes the expression $(n>=1)$ using Formula:

$$
\frac{1}{3^{2}}+\frac{1}{5^{2}}+\frac{1}{7^{2}}+\cdots+\frac{1}{(2 n+1)^{2}}
$$

The solution is shown in Fig. 4 and 5. 
Zavjalova et al., 2021. Ways of Using the Arduino Platform for Education of First-Year Students of the Riga Technical University

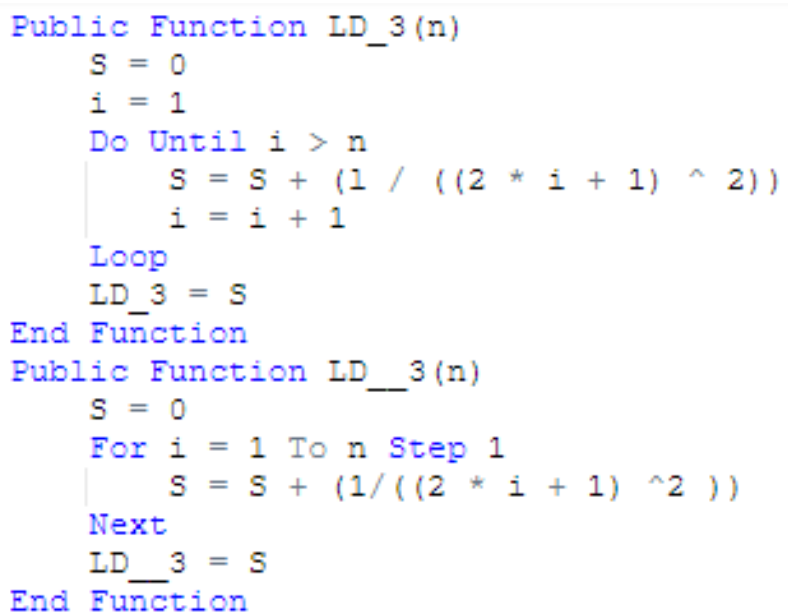

Figure 4 Solution Source Code

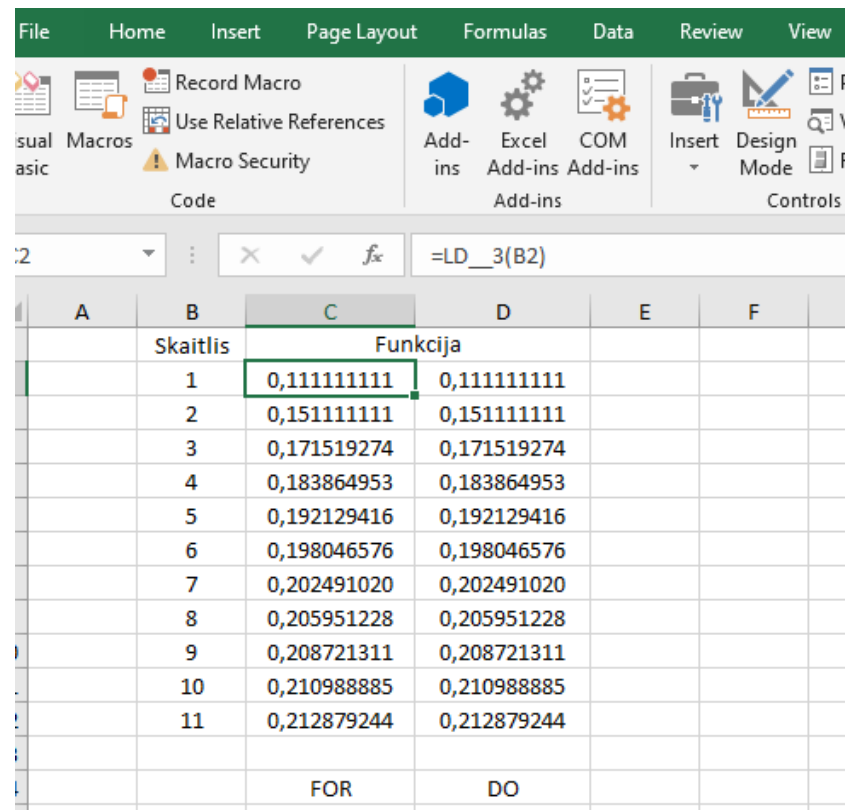

Figure 5 Created Table

Basically, the main purpose of the learning course "Computer Science" was reached. Students, performing laboratory work, received knowledge about programming algorithms and their use in programs. Also, students were given not only knowledge, but also experience in work with MS Excel. But the tasks themselves for laboratory work were associated either with mathematical formulas or the capabilities of MS Excel, i.e. assignments were not related to the real specialty of the first-year students - power and electrical engineering.

The same problem was pointed out by a survey of students, which is conducted every academic year. Data from a survey of students is given in Table 1. As already mentioned since 2019 academic year, the second study scheme based on the Arduino hardware platform has been used. 
To the question "As a result of mastering the study course "Computer Science", did you receive useful experience and assistance in mastering other study courses in your specialization?" the answers were divided as follows (Table 1):

Table 1 Survey Results

\begin{tabular}{|c|c|c|c|}
\hline Academic year & $\begin{array}{c}\text { Total number of } \\
\text { respondents }\end{array}$ & $\begin{array}{c}\text { Total number of } \\
\text { positive answers }\end{array}$ & Percentage ratio \\
\hline $2017 / 2018$ & 52 & 38 & $73.08 \%$ \\
\hline $2018 / 2019$ & 55 & 39 & $70.91 \%$ \\
\hline $2019 / 2020$ & 67 & 58 & $86.56 \%$ \\
\hline
\end{tabular}

To the question "Would you like to continue studying the course “Computer Science” students answered as follows (Table 2):

Table 2 Survey Results

\begin{tabular}{|c|c|c|c|}
\hline Academic year & $\begin{array}{c}\text { Total number of } \\
\text { respondents }\end{array}$ & $\begin{array}{c}\text { Total number of } \\
\text { positive answers }\end{array}$ & Percentage ratio \\
\hline $2017 / 2018$ & 52 & 39 & $75.00 \%$ \\
\hline $2018 / 2019$ & 55 & 40 & $72.73 \%$ \\
\hline $2019 / 2020$ & 67 & 62 & $92.54 \%$ \\
\hline
\end{tabular}

Based on these feedback data, the authors concluded that applying the learning scheme, aimed at gaining practical experience in the specialty, is really appropriate and useful for students.

For the technical support of this scheme, the department purchased Arduino kits. The Fig. 6 shows a learning place for students in the specialty Power and electrical engineering.

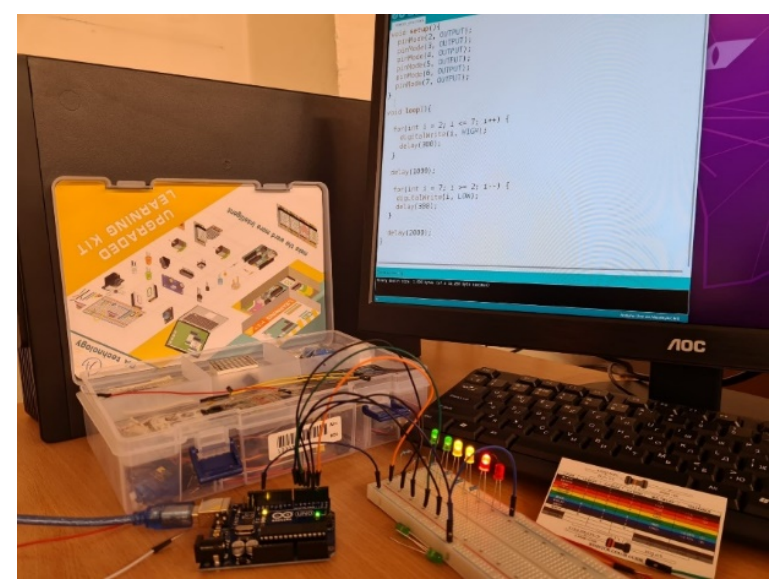

Figure 6 Workplace of Students for Performing Laboratory Work 
Zavjalova et al., 2021. Ways of Using the Arduino Platform for Education of First-Year Students of the Riga Technical University

Classes were also held in a computer class, where each student was provided with an Arduino set, and students worked in the Arduino IDE, solving various applied problems in a laboratory work.

The substantive part of the second study scheme also includes topics: branched and cyclic algorithms, nested loops, information processing in arrays, etc. But the Arduino platform uses $\mathrm{C} / \mathrm{C}++$ for programming. Therefore, students additionally mastered the new programming language.

Further examples of tasks for a solution based on the Arduino platform are given.

Task 1. Use the cycle to output all numbers divisible by 3 without remainder, in the range 1 to 20. Determine the quantity of these numbers and make the LED flash exactly as many times. The solution is shown in Fig. 7.
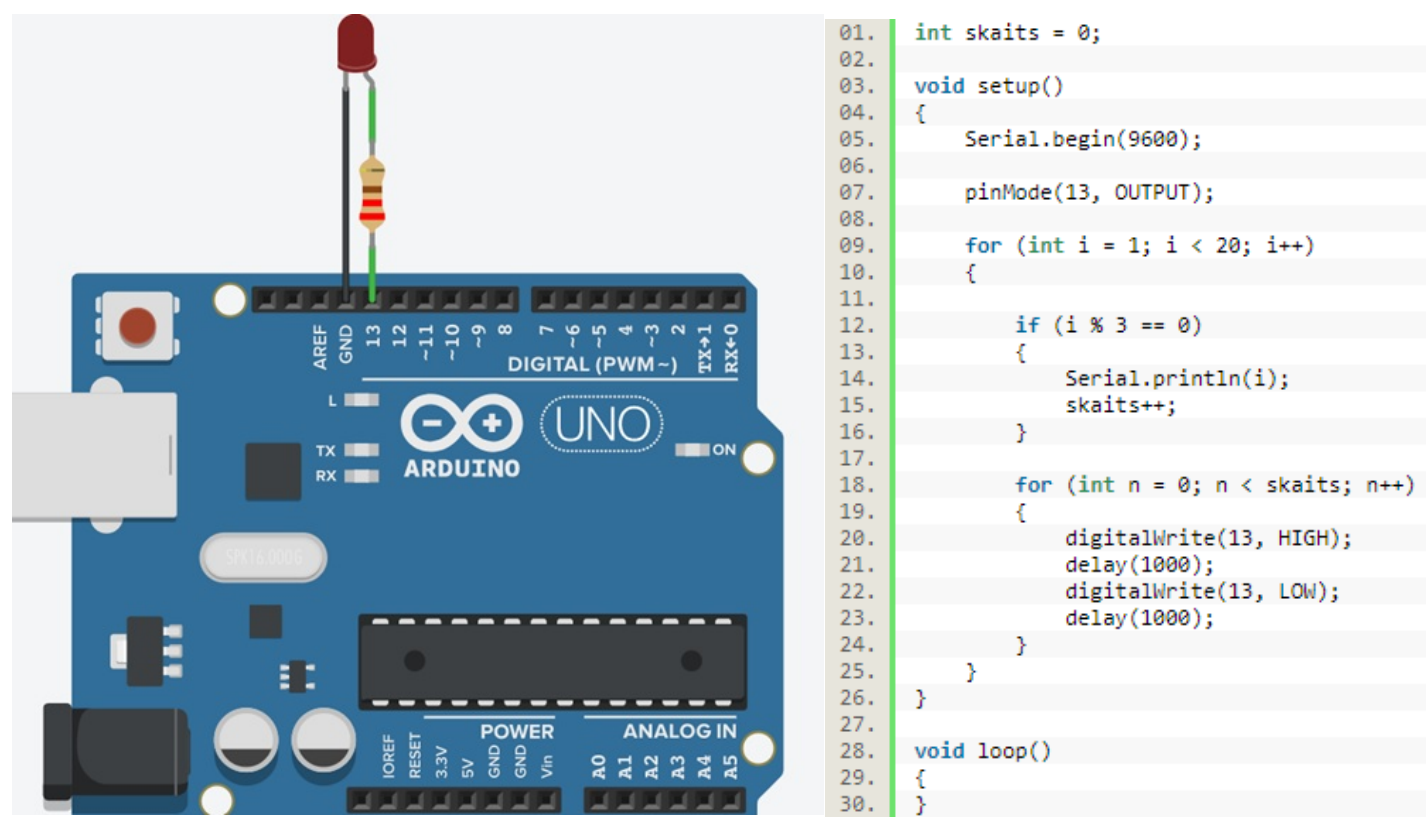

Figure 7 Solution Source Code and Created Scheme

Task 2. The traffic light should start with the green diode. Turn it on. After the set time $(10 \mathrm{sec})$ the diode starts flashing (three times with an interval of 3 sec). The green diode was turned off and the yellow diode was turned on. After the set time $(5 \mathrm{sec}$ ) the diode starts flashing (three times with an interval of 3 sec). The yellow diode was turned off and the red diode was turned on. After the set time $(10 \mathrm{sec})$ the diode starts flashing (three times with an interval of $3 \mathrm{sec}$ ). The red diode was turned off and the green diode was turned on. The solution is shown in Fig. 8. 
SOCIETY. INTEGRATION. EDUCATION

Proceedings of the International Scientific Conference. Volume V, May $28^{\text {th }}-29^{\text {th }}$, 2021. 511-521

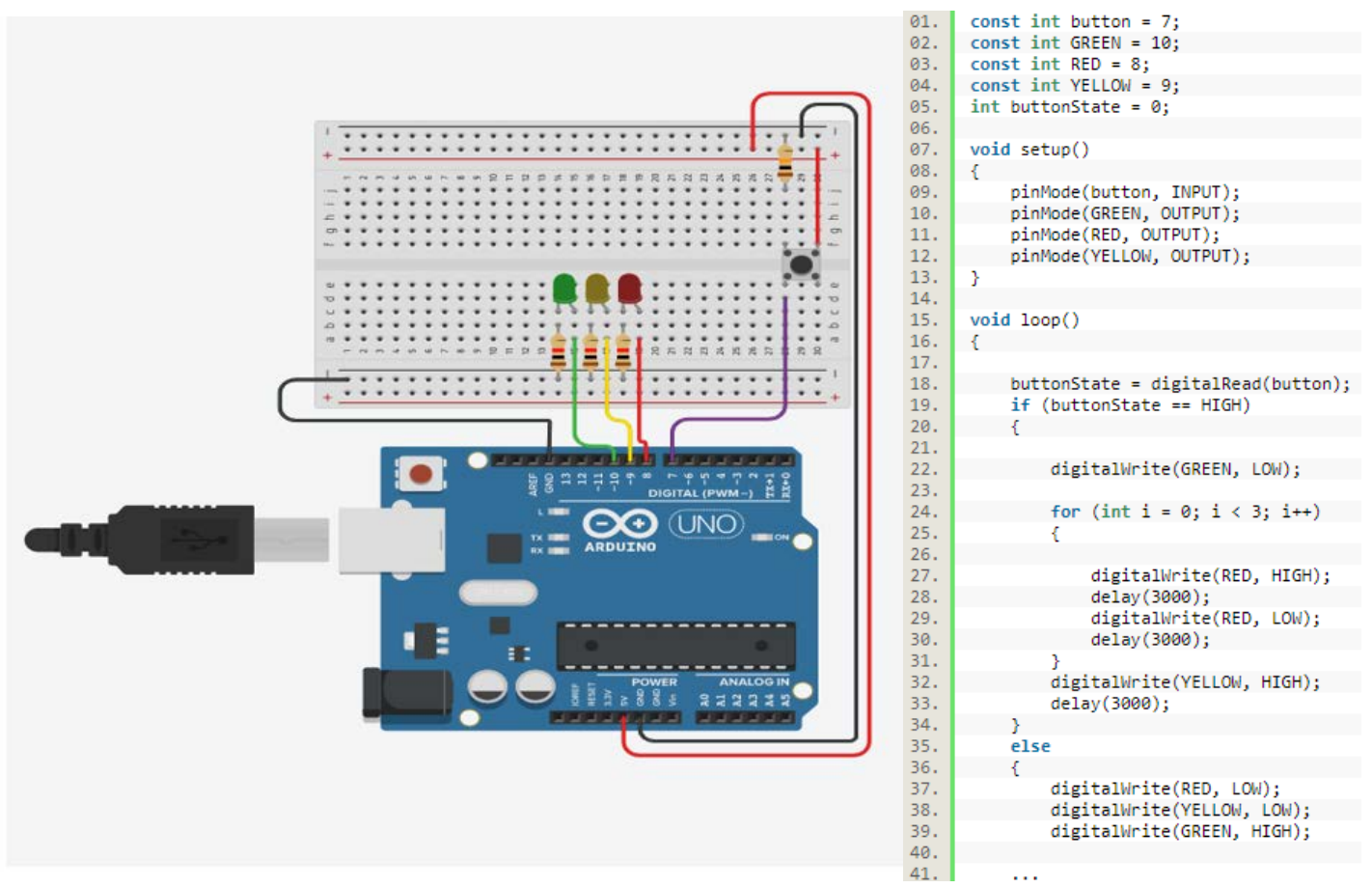

Figure 8 Solution Source Code and Created Scheme

Task 3. Connect 2 LEDs (red and green) to the circuit. Check numbers within a specified range (numbers are integers (int)). If there are more even numbers turn on the red diode, otherwise - the green. Range limits are entered in the code section, the user has nothing to enter after running the program. The solution is shown in Fig. 9.

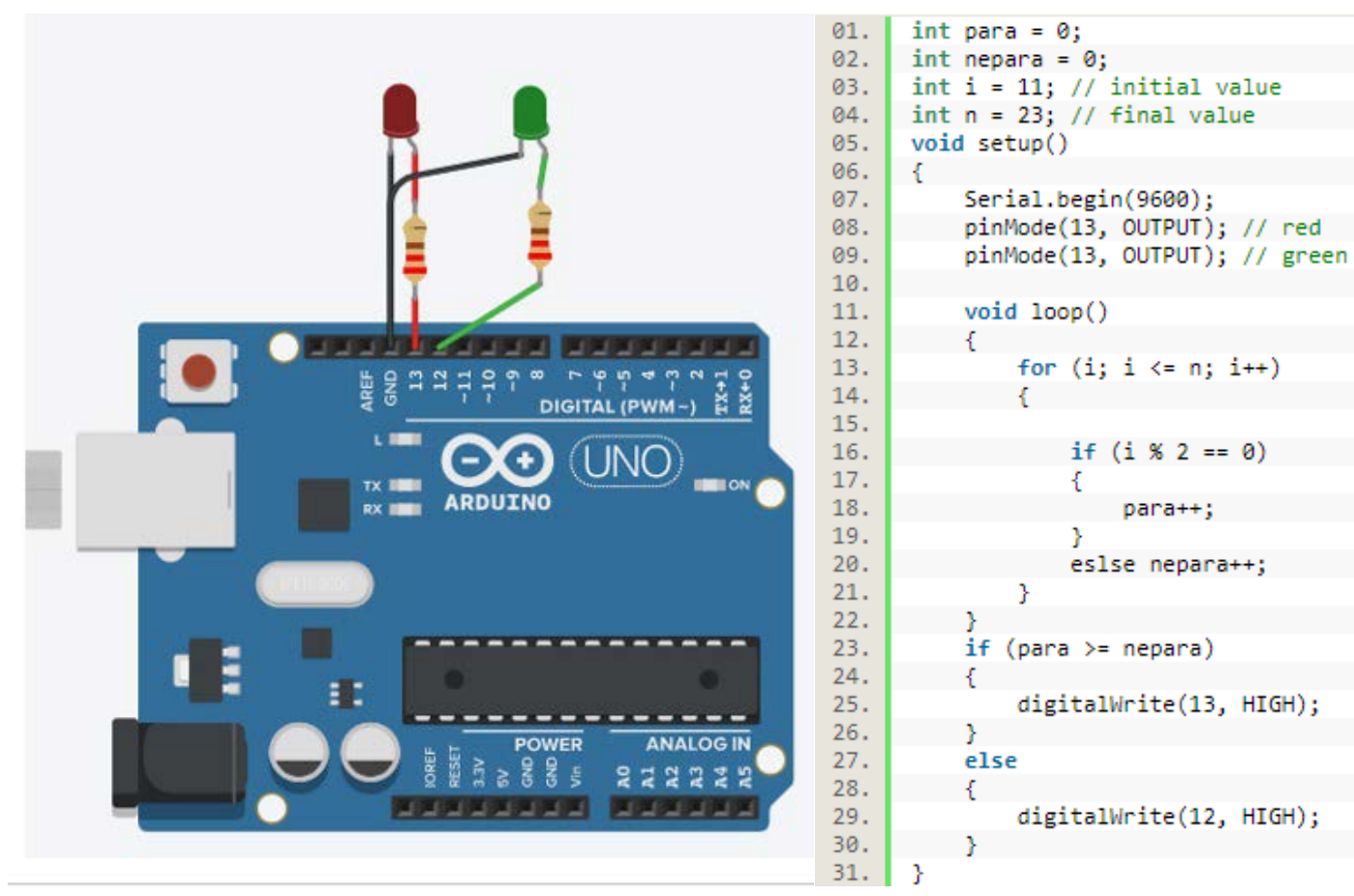

Figure 9 Solution Source Code and Created Scheme 
Zavjalova et al., 2021. Ways of Using the Arduino Platform for Education of First-Year Students of the Riga Technical University

Thus, although the proposed tasks for each study scheme allow students to compose the simplest algorithms and solve simple programming problems, the second scheme makes it possible to link the developed algorithms with the students' specialty and provides visual solutions to problems in the form of electrical circuits and boards.

\section{Conclusion}

As already mentioned, the ability to solve professional problems is very important for students of any specialty. Tasks when it is necessary to visualize electrical or physical processes require not only knowledge of a programming language, but also the ability to apply such computer technologies as, for example, Arduino. As can be seen, the Arduino IDE allows to display the solution to a problem both in the form of program code and visually in the form of a diagram. At the same time, students independently design the board and see the result of the solution in the form of signal processing (Fig. 6-8).

Using the Arduino platform as an example, the study course "Computer Science" clearly explains the mechanism of interaction between an electrical appliance and a computer, based on reading the initial data directly from the electric sensors (without manual input) for their further processing in the program code and on the output of the work result as a direct execution by the device described in the program code of the algorithm.

The survey of students also showed that they welcome such innovations in the educational process and willingly draw up different schemes.

Based on aforesaid, the authors conclude that the use of the second study scheme is advisable for first-year students of the Faculty of Electrical and Environmental Engineering.

Further work in this direction involves the development and use of a larger number of applied problems, taking into account the specifics of a particular specialty, to be solved in the Arduino IDE.

\section{References}

Engineering Experiences. (2020). Advantages and Disadvantages of Using Arduino. Retrieved from https://engineerexperiences.com/advantages-and-disadvatages.html.

Byungura, J.C., Hansson, H., Muparasi, M., \& Ruhinda, B. (2018). Familiarity with Technology among First-Year Students in Rwandan Tertiary Education. The Electronic Journal of e-Learning, 16 (1), 30-45.

Hammad, R., \& Munir, K. (2018). TELTSA-Technology Enhanced Learning: Theories, Systems, and Applications Special Track along with. The Eighth International Conference on Business Intelligence and Technology.

Hurtuk, J., Chovanec, M., \& Adam, N. (2017). The Arduino Platform Connected to Education Process. In INES: 2017 IEEE 21st International Conference on Intelligent Engineering 
Systems: 20-23 October 2017, Larnaca, Cyprus. Piscataway, NJ: Institute of Electrical and Electronics Engineers. Retrieved from https://ieeexplore.ieee.org/stamp/ stamp.jsp?tp $=\&$ arnumber $=8118531$

Microsoft Ignito. (2020). Getting started with VBA in Office. Retrieved from https://docs.microsoft.com/en-us/office/vba/library-reference/concepts/getting-startedwith-vba-in-office

Prokofyeva, N., Uhanova, M., Zavjalova, O., \& Boltunova, V. (2019). The Impact of Feedback on the Structuring Process of Study Courses. In Uskov V., Howlett R., Jain L. (Eds.) Smart Education and e-Learning 2019, Smart Innovation, Systems and Technologies, Volume 144. Springer, Singapore. DOI: https://doi.org/10.1007/978-98113-8260-4_39

Prokofjeva, N., Uhanova, M., Zavjalova, O., \& Katalnikova, S. (2015). Structuration of Courses at Studying Disciplines of Programming. Proceedings of the $10^{\text {th }}$ International Scientific and Practical Conference. Environment. Technology. Resources, Volume III, 159-163, ISBN 978-9984-44-173-3, ISSN 1691-5402. Retrieved from http://journals.ru.lv/index.php/ETR/article/view/179/709

Shadiev, R., Zhang, Z.H., Wu, T.-T., \& Huang, Y.M. (2020). Review of Studies on Recognition Technologies and Their Applications Used to Assist Learning and Instruction. Educational Technology \& Society, 23(4), 59.

Arduino. (2020). What is Arduino? Retrieved from https://www.Arduino.cc/en/ Guide/Introduction 